\title{
Inhibition of CPP32-Like Proteases Rescues Axotomized Retinal Ganglion Cells from Secondary Cell Death In Vivo
}

\author{
Pawel Kermer, Nikolaj Klöcker, Monika Labes, and Mathias Bähr \\ Department of Neurology, Universität Tübingen, 72076 Tübingen, Germany
}

The majority of retinal ganglion cells (RGCs) degenerate and die after transection of the optic nerve $(\mathrm{ON})$ in the adult rat. This secondary cell death can primarily be ascribed to apoptosis. Recent work strongly suggests a decisive role for a family of cysteine proteases, termed caspases, as mediators of neuronal apoptosis. In this study, we investigated whether activation of caspases contributes to delayed death of RGCs after axotomy. Intraocular application of various caspase inhibitors rescued up to $34 \%$ of RGCs that would otherwise have died $14 \mathrm{~d}$ after ON transection. Using a modified affinity-labeling technique, we detected a $17 \mathrm{kDa}$ protease subunit upregulated after axotomy. Upregulation was prevented by caspase inhibitor treatment. The $17 \mathrm{kDa}$ protein was identified as a CPP32-like protease by Western blot analysis and affinity labeling with biotinylated

Apoptosis or programmed cell death (PCD) is a fundamental and essential process in the development and tissue homeostasis of multicellular organisms. Dysregulation of apoptosis, however, is involved in various diseases such as neurodegenerative disorders and neuronal trauma (Thompson, 1995; Vasilakos and Shivers, 1996). Investigation of the mechanisms underlying apoptosis led to the discovery of various mammalian cysteine proteases now called caspases (Yuan et al., 1993; Alnemri et al., 1996; for review, see Cohen, 1997). Interleukin-1 $\beta$-converting enzyme (ICE) was first identified as an apoptosis-inducing protease attributable to significant sequence homology with ced-3, the well known cell death gene of the nematode Caenorhabditis elegans, which mediates PCD during development (Yuan et al., 1993). In addition to ICE, at least nine caspases have been found so far that can be divided into three subgroups based on phylogenic relationship and sequence homology: ICE-like proteases, CPP32-like proteases, and Nedd2-like proteases (Alnemri et al., 1996; for review, see Cohen, 1997). Recent data show that caspases are important mediators of neuronal apoptosis (for review, see Martinou and Sadoul, 1996; Srinivasan et al., 1996; Keane et al., 1997). Ischemic brain injury results in protease upregulation (Bhat et al., 1996; Asahi et al., 1997; Kinoshita et al., 1997), and inhibition of these proteases proved to be neuroprotective in vitro and in vivo (Milligan et al., 1995; Schulz et al., 1996; Slee et al., 1996; Taylor et al., 1997). Cowpox ICE-inhibitor CrmA, for instance, protected chicken dorsal root ganglion cells from death after neurotrophic

\footnotetext{
Received Oct. 2, 1997; revised Feb. 18, 1998; accepted March 26, 1998.

This work was supported by grants from the Bundesministerium für Bildung, Wissenschaft, Forschung und Technologie (Neurotraumatologie to M.B. and 01KS 9602 to N.K.). We thank S. Thomsen for technical assistance and M. Rott and J. B. Schulz for critical readings of this manuscript.

Correspondence should be addressed to Mathias Bähr, Department of Neurology, Universität Tübingen, Hoppe-Seyler-Strasse 3, 72076 Tübingen, Germany.

Copyright (C) 1998 Society for Neuroscience $0270-6474 / 98 / 184656-07 \$ 05.00 / 0$
}

acetyl-Asp-Glu-Val-Asp-aldehyde, which specifically inhibits CPP32-like caspases. In vivo application of the irreversible caspase inhibitor benzyloxycarbonyl-Asp-Glu-Val-Asp-chloromethylketone revealed CPP32-like proteases to be major mediators of caspase-induced apoptosis in axotomized RGCs, because this inhibitor showed an even higher neuroprotective potential than the irreversible wide-range inhibitor benzyloxycarbonyl-Val-Ala-DL-Asp-fluoromethylketone. In summary, the data presented here provide further insight into the mechanisms of injury-induced neuronal apoptosis and could give rise to more effective therapeutic intervention strategies in CNS trauma and neurodegenerative diseases.

Key words: caspases; protease-inhibitor; CPP32; apoptosis; retinal ganglion cells; axotomy; neuroprotection

factor deprivation in vitro (Gagliardini et al., 1994). Moreover, naturally occurring cell death of developing motoneurons in chicken was prevented by caspase inhibition in vivo (Milligan et al., 1995). In addition, application of a protease inhibitor also had neuroprotective effects in ischemic brain damage (Hara et al., 1997a).

In the adult mammalian CNS, fiber tract lesions often induce secondary degeneration and death of the parental neurons. For example, transection of the optic nerve $(\mathrm{ON})$ results in delayed death of $\sim 80 \%$ of retinal ganglion cells (RGCs), primarily attributable to apoptosis (Garcia-Valenzuela et al., 1994; Rabacchi et al., 1994; Isenmann et al., 1997). Therefore, it is of great interest and importance to investigate the potential role of caspases in axotomy-induced apoptosis. In the present report, we studied the in vivo effects of protease inhibitors on the survival of axotomized RGCs and analyzed the proteases mediating postlesional apoptosis in greater detail by affinity labeling.

\section{MATERIALS AND METHODS}

Optic nerve transection. Surgery was performed as described in detail elsewhere (Klöcker et al., 1997). Briefly, adult female Sprague Dawley rats (200-250 gm) purchased from Charles River Wiga (Sulzfeld, Germany) were anesthetized by intraperitoneal injection of chloral hydrate $(0.42 \mathrm{gm} / \mathrm{kg}$ body weight $)$. After skin incision close to the superior orbital rim, the orbita was opened, taking care to leave the supraorbital vein intact. After subtotal resection of the lacrimal gland, the superior extraocular muscles were spread by means of a small retractor. The ON was exposed by longitudinal incision of the eye retractor muscle and the perineurium. ON transection was performed $\sim 2 \mathrm{~mm}$ from the posterior pole of the eye without damaging retinal blood supply. Animals with persistent retinal ischemia verified funduscopically were not included in the study.

Retrograde labeling of retinal ganglion cells. To allow accurate counting of RGCs, cells were retrogradely labeled by the fluorescent tracers 1,1'-dioctadecyl-3,3,3' $3^{\prime}$-tetramethylindocarbocyanine perchlorate (DiI; Molecular Probes, Eugene, OR) and fast blue (FB; Dr. Illing Chemie, 
Gross-Umstadt, Germany). The skull cartilage of rat pups (postnatal day 7) was opened dorsal to the $\lambda$ fissure under diethylether anesthesia, and both superior colliculi were instilled with $5 \%$ DiI in dimethylformamide using a micropipette. Retrograde labeling with FB was achieved by placing a small piece of gel foam soaked in $2 \%$ aqueous $\mathrm{FB}$ at the ocular stump of the axotomized ON.

Drug administration. The irreversible wide-range protease inhibitor benzyloxycarbonyl-Val-Ala-DL-Asp-fluoromethylketone (ZVAD-fmk; Bachem) as well as the reversible and irreversible inhibitors of CPP32like caspases acetyl-Asp-Glu-Val-Asp-aldehyde and benzyloxycarbonylAsp-Glu-Val-Asp-chloromethylketone (DEVD-CHO and ZDEVDcmk, respectively; Bachem) were dissolved in $2 \%$ dimethylsulfoxide (DMSO; Sigma, Deisenhofen, Germany) in PBS. All these inhibitors effectively block the intracellular activation of caspases, as shown in several studies on apoptotic cell death in various types of tissue (Roquet et al., 1996; Schulz et al., 1996; Slee et al., 1996; Tomita et al., 1996; Armstrong et al., 1997). Whereas peptides with an aldehyde moiety are reversible protease inhibitors, those with a fluoromethylketone or chloromethylketone moiety bind to caspases irreversibly (Armstrong et al., 1997; Cohen et al., 1997; Nicholson et al., 1997). An additional benzyloxycarbonyl group (indicated as $\mathrm{Z}$ in the above abbreviations) further improves their cell permeability (Zhu et al., 1995; Armstrong et al., 1996; Slee et al., 1996; for review, see Cohen, 1997).

For intraocular injection of inhibitors or vehicle (2\% DMSO in PBS), animals were anesthetized with diethylether. By means of a glass microelectrode with a tip diameter of $30 \mu \mathrm{m}, 2 \mu \mathrm{l}$ of caspase inhibitors or $2 \mu \mathrm{l}$ of vehicle was injected into the vitreous space, puncturing the eye at the cornea-sclera junction.

We used two different doses of ZVAD-fmk (400 or $4000 \mathrm{ng}$ /injection, which for all the inhibitors used resulted in final vitreous body concentrations slightly above those used in vitro), each in two different regimens for ZVAD-fmk-vehicle treatment: animals either received (1) three intraocular injections of ZVAD-fmk-vehicle on days 4, 7, and 10 after axotomy or (2) four intraocular injections on days $0,4,7$, and 10 after axotomy.

In another set of experiments we injected $4000 \mathrm{ng}$ of DEVD-CHO or ZDEVD-cmk, both of which are protease inhibitors specific for CPP32like caspases, on days $0,4,7$, and 10 after axotomy (treatment 2).

Animals receiving $4000 \mathrm{ng}$ Z-Phe-cmk served as additional controls.

Tissue processing. Fourteen days after ON transection, animals received an overdose of chloral hydrate, and the eyes were removed. The retinae were dissected, flat-mounted on gelatin-coated glass slides, and fixed for $20 \mathrm{~min}$ in $4 \%$ paraformaldehyde in PBS. RGCs were examined under the fluorescence microscope (Axiovert 35; Zeiss) using a rhodamine filter $(546 / 590 \mathrm{~nm})$ for DiI fluorescence and a DAPI filter $(365 / 420$ $\mathrm{nm}$ ) for FB fluorescence, respectively. The number of DiI- or FB-positive RGCs was determined by counting them in 12 distinct areas of 62,500 $\mu \mathrm{m}^{2}$ each (three areas per retinal quadrant at three different eccentricities of one-sixth, one-half, and five-sixths of the retinal radius). Cell counts were performed according to a double-blind protocol and by two different investigators. Overestimation of RGC density by retinal shrinkage attributable to intraocular injection was excluded (Klöcker et al., 1998).

Affinity labeling. For this set of experiments retinae were explanted on day 4 after lesion after the eyes had received an injection of $4000 \mathrm{ng}$ of ZVAD-fmk on days 0 and 4 after axotomy. They were homogenized immediately in ice-cold lysis buffer containing $150 \mathrm{~mm} \mathrm{NaCl}, 50 \mathrm{~mm}$ Tris, $\mathrm{pH}$ 8.0, 2 mM EDTA, and 1\% Triton X-100 containing 0.1 mM PMSF and $2 \mu \mathrm{g} / \mathrm{ml}$ pepstatin, leupeptin, and aprotinin. The cell suspension was lysed on ice for $20 \mathrm{~min}$, and cell debris was pelleted for $15 \mathrm{~min}$ at $14,000 \times g$. The protein concentration of the supernatant was determined using the BCA reagent (Pierce, Rockford, IL), and $200 \mathrm{ng}$ of protein was subjected to affinity labeling with biotinylated protease inhibitors. BiotinAc-Tyr-Val-Ala-Asp-chloromethylketone (bio-YVAD-cmk; Bachem) and biotin-Ac-Asp-Glu-Val-aspartic acid aldehyde (bio-DEVD-CHO; Bachem) were added to a final concentration of $20 \mathrm{nM}$, and the suspension was incubated at room temperature (RT) for 30 min with constant agitation. Labeled proteins were then affinity-purified on streptavidin (SA) M-280 dynabeads (diameter, $2.8 \mu \mathrm{m}$; density, $1.3 \mathrm{gm} / \mathrm{cm}$; concentration, $10 \mu \mathrm{g} / \mu \mathrm{l}$; Dynal, Oslo, Norway). Twenty microliter dynabeads were washed once with binding and washing buffer (BWB; $5 \mathrm{~mm}$ Tris$\mathrm{HCl}, \mathrm{pH} 7.5,0.5 \mathrm{~mm}$ EDTA, and $1 \mathrm{M} \mathrm{NaCl}$ ) and added to the lysate, which had been adjusted to $1 \times$ BWB by adding 1 volume of $2 \times$ BWB. The mixture was again incubated at RT for $30 \mathrm{~min}$ with constant shaking. Bound proteins were washed four times with BWB using a magnetic separator, resuspended in $1 \times$ denaturing protein loading buffer, and subjected to SDS-PAGE.

Western blotting. After separation by SDS-PAGE (Ausubel et al., 1987) of either lysate $(50 \mu \mathrm{l})$ or purified, affinity-labeled samples, proteins were transferred to a nitrocellulose or polyvinylidene difluoride (PVDF) membrane and blocked with 5\% skim milk in PBS-Tween 20 (PBS-T; $0.1 \%$ Tween 20). Labeled proteins were detected by incubating with SA-HRP (1:5000 in PBS-T) for $1 \mathrm{hr}$, washing three times in PBS-T, and applying the ECL-Plus reagent (Amersham, Arlinghton Heights, IL) according to the supplier's instructions.

In a second set of experiments retinae were homogenized as described above. Lysates were extracted, and $50 \mu \mathrm{g}$ of protein was separated on a $12 \%$ SDS gel without previous inhibitor incubation. Proteins were transferred on PVDF membranes as described above and incubated with rabbit-anti-CPP32 (1:2000; $3 \mathrm{hr}$ at RT; Upstate Biotechnology, Lake Placid, NY) followed by goat anti-rabbit HRP (1:2000; $1 \mathrm{hr}$ at RT).

Statistics. Data are given as mean \pm SEM. Statistical significance was assessed using one-way ANOVA followed by the Duncan test. For expressing RGC survival-promoting effects of protease inhibitors, we defined RGC rescue rate (RRR; Klöcker et al., 1997): RRR $=\left(N_{\text {ther }}-\right.$ $\left.N_{\text {con }}\right) /\left(N_{\text {tot }}-N_{\text {con }}\right) \times 100$, where $N_{\text {tot }}$ is the number of RGCs in unlesioned retinae, $N_{\text {con }}$ is the number of RGCs surviving without therapy, and $N_{\text {ther }}$ is the number of RGCs surviving after a given therapy.

\section{RESULTS}

\section{Axotomy-induced retrograde death of RGCs}

In unlesioned control retinae, retrograde labeling of RGCs from the superior colliculi by the fluorescent tracer DiI resulted in a typical fine-dotted pattern of fluorescence of the RGC perikarya (Klöcker et al., 1997). The mean RGC density was $2080 \pm 69$ cells $/ \mathrm{mm}^{2}$. This number is in agreement with cell densities observed by other investigators (Eschweiler and Bähr, 1993; Mansour-Robaey et al., 1994). Within 14 d after ON transection, it decreased to $17 \%$ of control, as determined by retrograde FB labeling from the axon stump, which displayed a uniform labeling throughout the retina as observed with DiI but a more diffuse staining of perikarya (Table 1, Fig. 1). As has been observed earlier, lesion-induced RGC death was more pronounced at the inner retinal radius with $14 \%$ surviving RGCs compared with $24 \%$ of control at the outer retinal radius (Klöcker et al., 1997). RGCs appeared shrunken and hardly exposed any dendritic processes (Fig. 1a). Comparison of DiI and FB data are possible because it has been shown that both dyes have a similar label efficacy (Eschweiler and Bähr, 1993). Animals with persistent retinal ischemia or lacking uniform labeling of RGCs throughout the retina were excluded from the study.

\section{Effects of ZVAD-fmk on survival of axotomized RGCs}

Whereas three intraocular injections of vehicle did not significantly influence the survival of axotomized RGCs, three intraocular injections of $400 \mathrm{ng}$ of ZVAD-fmk on days 4, 7, and 10 after lesion led to a significantly higher mean RGC density with an RRR value of $12 \%$ (Table 1, Fig. 1). This rescue effect could not be improved by raising the dose of ZVAD-fmk to $4000 \mathrm{ng}$ (RRR $12 \%)$. However, starting ZVAD-fmk treatment immediately after surgery (4 intraocular injections on days $0,4,7$, and 10 after axotomy) significantly increased the RRR to $17 \%$ at $400 \mathrm{ng} /$ injection and to $22 \%$ at $4000 \mathrm{ng} /$ injection, again without statistical difference between the two doses. An additional vehicle injection had no effect (data not shown). The dependence of RGC rescue by ZVAD-fmk on the different treatment regimens is illustrated in Figure 2. In comparison with axotomy without therapy, many labeled RGCs appeared healthy and displayed a normal shape and dendritic arborization (Fig. 1b). 


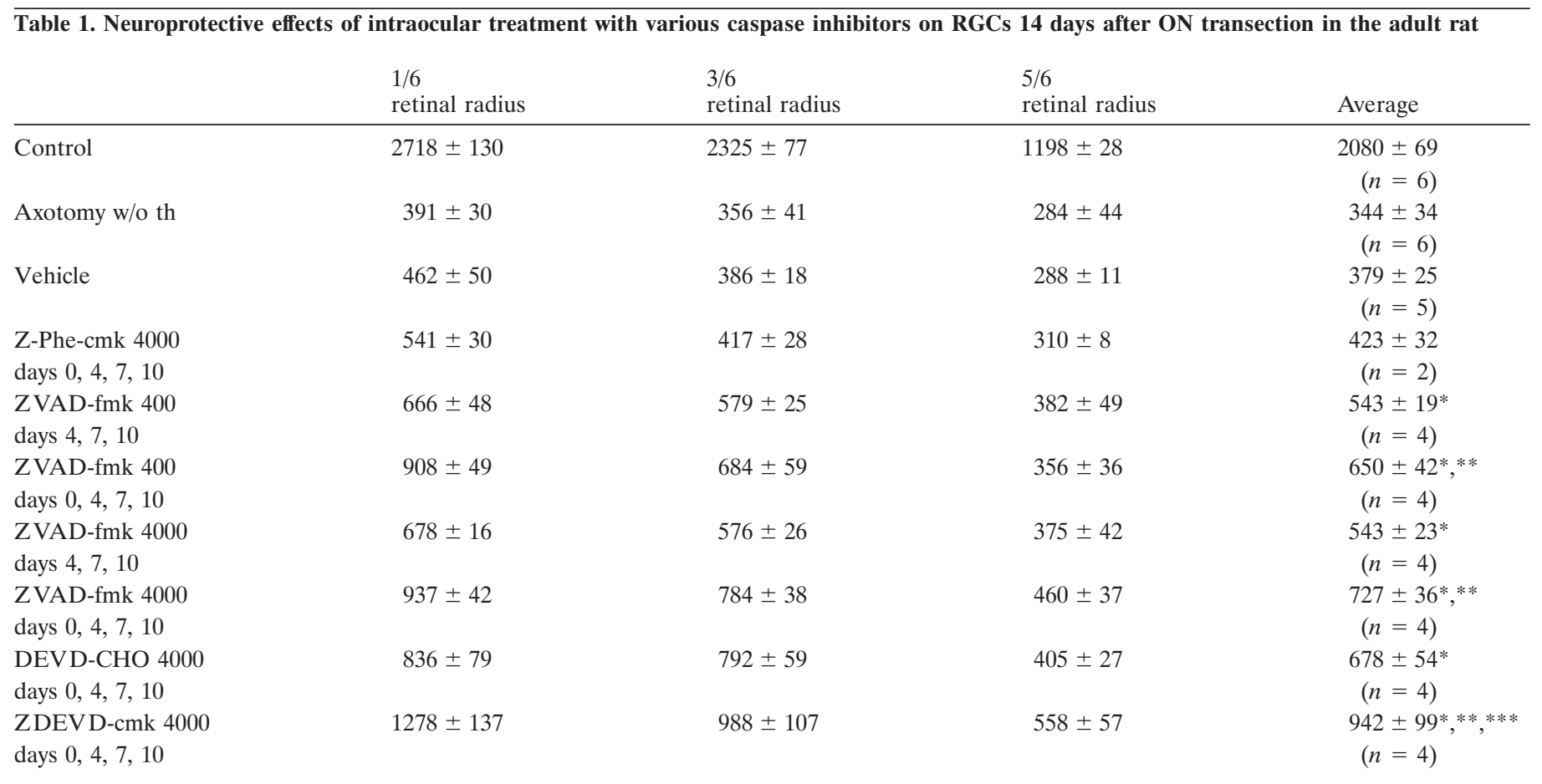

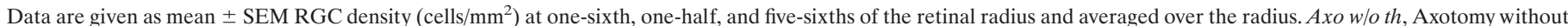

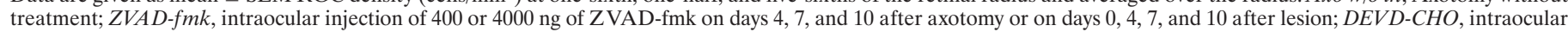

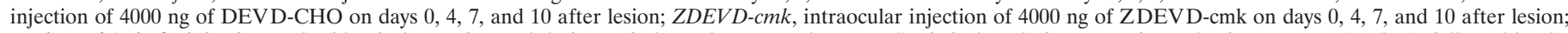

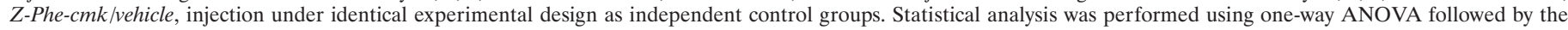
Duncan test.

${ }^{*} p<0.05$ when compared with axo w/o th or vehicle injection.

$* * p<0.05$ when compared with treatment on days 4,7 , and 10 after lesion

$* * *_{p}<0.05$ when compared with treatment with ZVAD-fmk on days 0, 4, 7 and 10 after lesion.

\section{Activation of CPP32 and CPP32-like caspase after ON transection}

To identify potential active proteases involved in the death of axotomized RGCs, we modified the affinity-labeling technique developed by Thornberry et al. (1994). Retinae were lysed on day 4 after $\mathrm{ON}$ transection and incubated with the biotinylated protease inhibitors YVAD-cmk or DEVD-CHO. With magnetic streptavidin beads it was possible to extract biotin-labeled active caspase subunits from total protein lysates before separation on SDS-PAGE.

Using bio-YVAD-cmk (Fig. $3 a$ ) we detected a labeled protein migrating at the molecular weight of $17 \mathrm{kDa}$. After axotomy, the amount of that protein was increased in comparison with unlesioned control retinae. By intraocular injection of $4000 \mathrm{ng}$ of ZVAD-fmk on days 0 and 4 after lesion this upregulation could be prevented (Fig. $3 a$ ). One known caspase that is cleaved to 17 and $12 \mathrm{kDa}$ subunits, respectively, is CPP32 (Enari et al., 1996). Although YVAD-cmk is a potent inhibitor of ICE-like caspases ( $K_{\text {iICE }}, 0.76 \mathrm{~nm}$; Rotonda et al., 1996), no cleavage product of ICE was detectable in any of our experiments.

In another set of experiments we used a biotinylated derivate of DEVD-CHO (Fig. 3b), a protease inhibitor specific for CPP32like caspases $\left(K_{\mathrm{iCPP} 32}, 0.35 \mathrm{~nm}\right.$; Rotonda et al., 1996). Again we observed a change in the amount of a $17 \mathrm{kDa}$ protease subunit as seen with bio-YVAD-cmk (Fig. 3a), supporting the hypothesis of an involvement of CPP32 and CPP32-like caspases in cell death after axotomy.

Indeed, active CPP32 could be detected by a specific antibody that detected the same purified $17 \mathrm{kDa}$ band after membrane stripping (data not shown), as well as in Western blotting experiments with fresh lysates. As shown in Figure $3 c$, axotomy resulted in an increase of the $17 \mathrm{kDa}$ fragment on blots treated with anti-CPP32. In agreement with the affinity-labeling experiments, this upregulation was blocked to a great extent by caspase inhibition with ZVAD-fmk. Again, there was a baseline activity of CPP32 in unlesioned controls. These results further underline the importance of CPP32 and CPP32-like caspases for neuronal apoptosis after axotomy in vivo.

\section{Specific inhibition of CPP32-like caspases promotes survival of axotomized RGCs}

After having demonstrated an axotomy-induced activation of CPP32 and CPP32-like caspases, we were interested in the neuroprotective effect of CPP32-inhibitors in vivo. In fact, intraocular injection of DEVD-CHO significantly promoted the survival of axotomized RGCs. Four injections (on days 0, 4, 7, and 10 after ON transection) of $4000 \mathrm{ng}$ of DEVD-CHO rescued $20 \%$ of the RGCs that would otherwise have died after axotomy (Table 1). This rescue rate did not differ significantly from the RRR achieved by ZVAD-fmk after the identical treatment protocol.

Under identical experimental paradigms, four injections of ZDEVD-cmk, an irreversible inhibitor of CPP32-like caspases, resulted in a further improvement of rescue effects. Compared with ZVAD-fmk or DEVD-CHO treatment the number of surviving RGCs increased significantly with a rescue rate of $34 \%$ (Table 1; Figs. 1c, 2).

To exclude potential rescue effects caused by halogenic methylketones, we applied Z-Phe-cmk in an additional set of control 

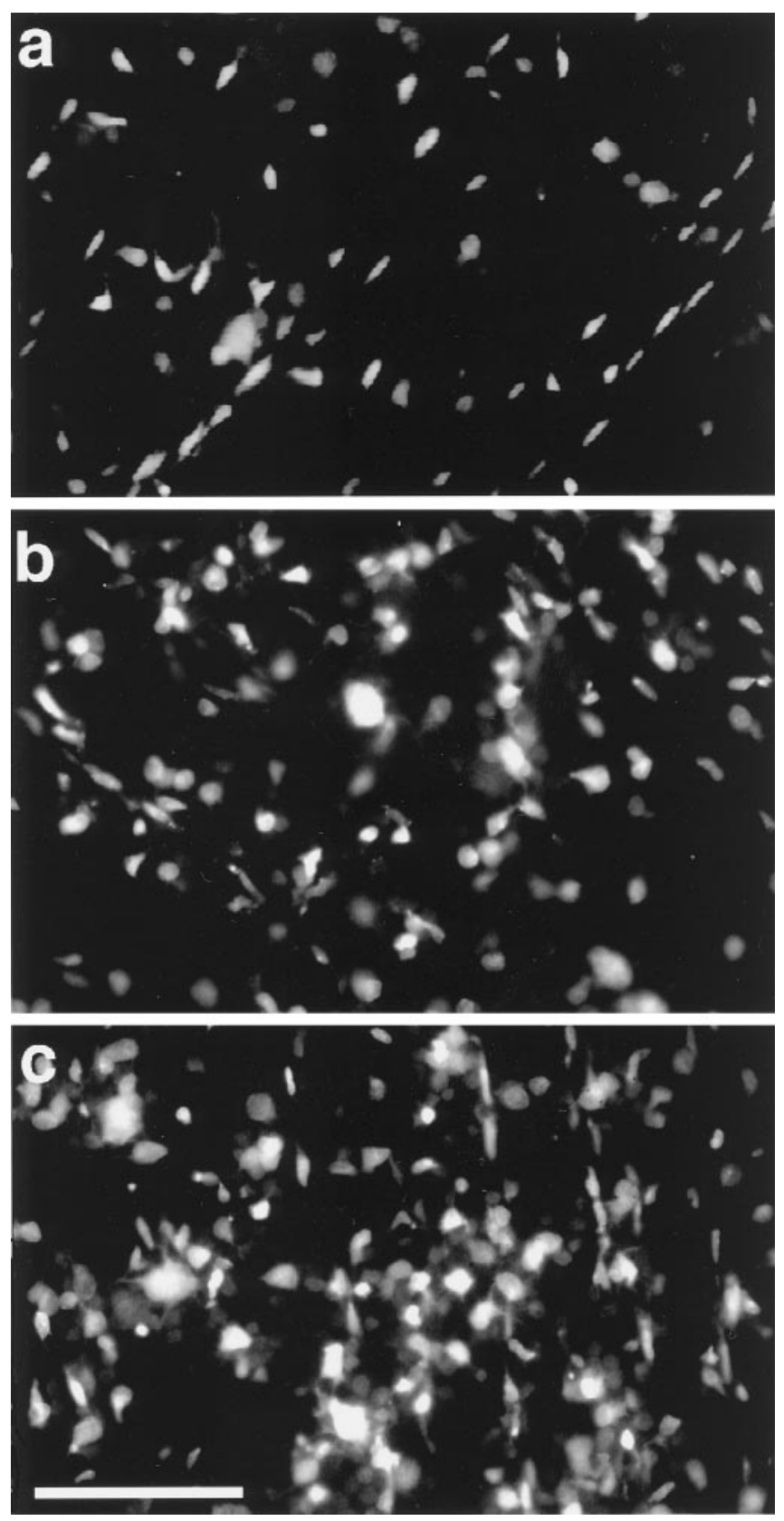

Figure 1. Representative micrographs of flat-mounted retinae at corresponding areas of one-half of the retinal radius $14 \mathrm{~d}$ after $\mathrm{ON}$ transection. RGCs are labeled retrogradely with the fluorescent tracer fast blue. $a$, Axotomy without treatment. $b$, Injection of $4000 \mathrm{ng}$ of ZVAD-fmk on days $0,4,7$, and 10 after lesion. $c$, Injection of $4000 \mathrm{ng}$ of ZDEVD-cmk on days $0,4,7$, and 10 after lesion. Note the higher density of RGCs in $c$ when compared with $a$ and $b$. Scale bar, $100 \mu \mathrm{m}$.

experiments. In agreement with Armstrong et al. (1997) no significant neuroprotective effect could be observed under these conditions when compared with axotomy without treatment.

\section{DISCUSSION}

In a number of studies, caspases have been shown to play a decisive role in mediating neuronal apoptosis (for review, see Martinou and Sadoul, 1996). We demonstrated for the first time that inhibition of caspases can rescue RGCs from secondary death after axonal lesion. Moreover, we identified CPP32-like

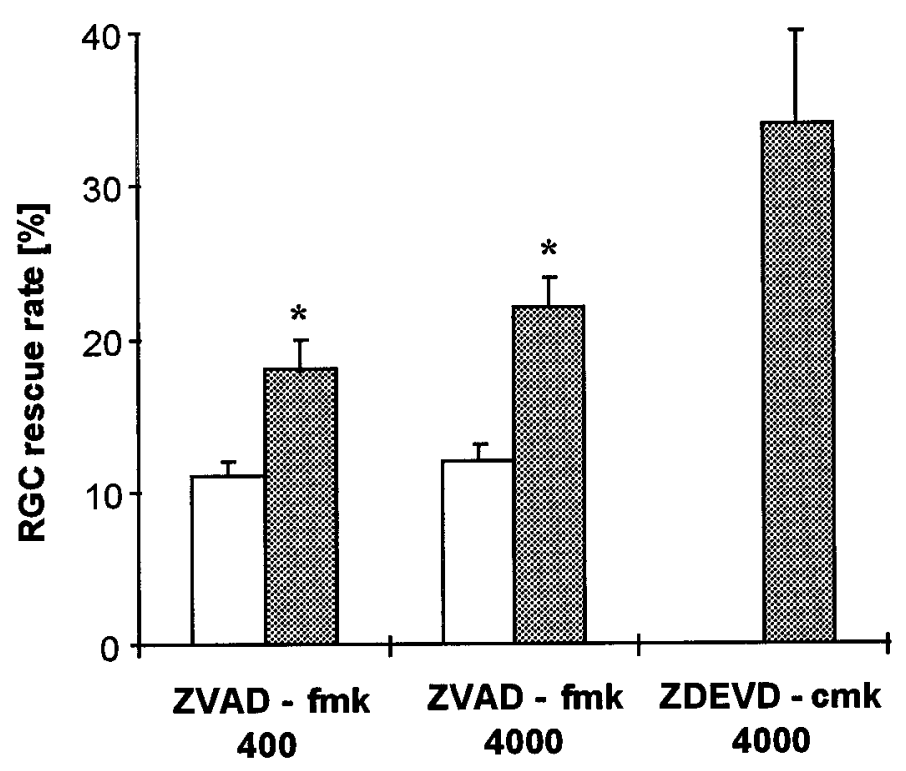

Figure 2. Rescue effects of ZVAD-fmk and ZDEVD-cmk treatment on axotomized RGCs $14 \mathrm{~d}$ after ON transection. Three intraocular injections on days 4, 7, and 10 after axotomy (white bars) of either 400 or $4000 \mathrm{ng}$ of ZVAD-fmk showed identical survival-promoting effects on lesioned RGCs when compared with untreated axotomy. An additional injection on day 0 after axotomy ( gray bars) significantly improved the postlesional survival of RGCs. Treatment with $4000 \mathrm{ng}$ of ZDEVD-cmk on postlesional days $0,4,7$, and 10 resulted in a RGC rescue rate of $34 \%$, which was statistically significant when compared with four injections of ZVAD-fmk ( gray bars $) . \mathrm{RRR}=\left(N_{\text {ther }}-N_{\text {con }}\right) /\left(N_{\text {tot }}-N_{\text {con }}\right) \times 100$, where $N_{\text {tot }}$ is the number of RGCs in unlesioned retinae, $N_{\text {con }}$ is the number of RGCs surviving without therapy, and $N_{\text {ther }}$ is the number of RGCs surviving after a given therapy. Data are given as mean \pm SEM. Asterisks indicate significant differences between intraocular injection on days 4,7 , and 10 and additional injection on day 0 after ON transection. $p<0.05$.

proteases as major mediators of caspase-regulated apoptosis in axotomized RGCs.

Because of good surgical accessibility, the retino-tectal projection in the rat serves as a convenient model to study degenerative and regenerative processes in the mammalian CNS (VillegasPerez et al., 1988; Mey and Thanos, 1993; Bähr and Bonhoeffer, 1994; Bähr and Wizenmann, 1996). Axotomy of all RGCs by ON transection results in the delayed death of $\sim 80 \%$ of RGCs (Eschweiler and Bähr, 1993; Mansour-Robaey et al., 1994; Cui and Harvey, 1995). Experimental evidence indicates that this secondary death can be ascribed primarily to apoptosis (GarciaValenzuela et al., 1994; Rabacchi et al., 1994; Isenmann et al., 1997), which can be prevented in adult mice overexpressing the antiapoptotic proto-oncogene bcl-2 (Cenni et al., 1996).

Recent in vivo data demonstrate that inhibition of caspases, which are activated in ischemic brain injury (Bhat et al., 1996; Asahi et al., 1997; Kinoshita et al., 1997), can protect the affected neurons, thus possibly representing a new therapeutic option in neuronal trauma (Hara et al., 1997a). To test whether similar mechanisms underlie neuronal apoptosis induced by axonal injury, after ON transection in rats we applied the irreversible wide-range protease inhibitor ZVAD-fmk, which has a good cell permeability attributable to its benzyl-oxycarbonyl group (Zhu et al., 1995; Cohen, 1997) and is proven to support RGC survival in vitro (Chen et al., 1997). In the first approach, we designed a treatment regimen consisting of three single intraocular injections on days 4, 7, and 10 after lesion because (1) apoptotic death of axotomized RGCs can first be detected at day 4 and reaches a 
a

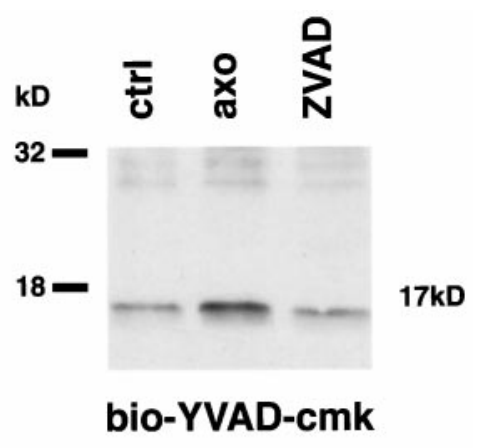

b

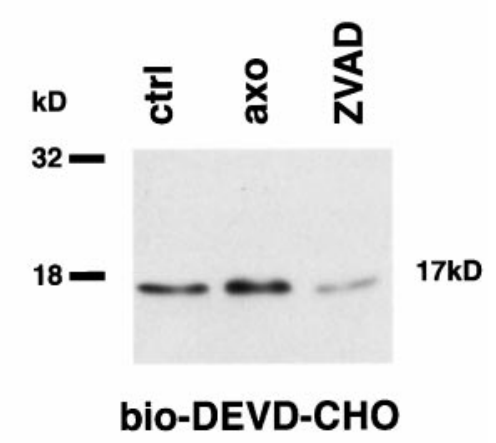

C

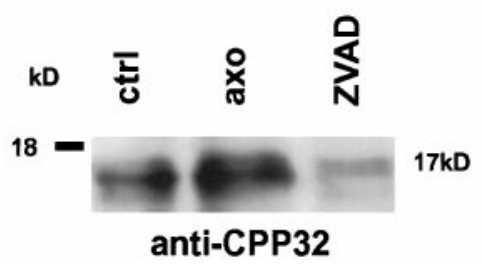

Figure 3. Affinity labeling of activated retinal proteases $14 \mathrm{~d}$ after ON transection. $a$, Affinity labeling with biotinylated YVAD-cmk. Note the upregulation of an active protease with a molecular weight of $17 \mathrm{kDa}$ after axotomy. Under treatment with ZVAD-fmk this upregulation is clearly inhibited. $b$, Affinity labeling with biotinylated DEVD-CHO, a specific inhibitor for CPP32-like caspases. Again, one can detect the identical regulation of an active protease at $17 \mathrm{kDa}$ as described in $a$. $c$, Western blot with an antibody against CPP32. Note the identical regulation of active CPP32 as described in $a$ and $b$. ctrl, Untreated control; axo, axotomy without treatment; ZVAD, injection of $4000 \mathrm{ng}$ of ZVAD-fmk on days 0 and 4 after axotomy.

maximum at day 7 after axotomy (Isenmann et al., 1997); and (2) other neuroprotectants antagonizing apoptosis, such as brainderived neurotrophic factor, show the same rescue effects when injected on day 0,3 , or 5 after lesion (Mansour-Robaey et al., 1994). ZVAD-fmk treatment, starting on day 4 after surgery, led to a significant increase in the number of surviving RGCs when compared with axotomized but untreated or sham-treated retinae. In another set of experiments, ZVAD-fmk was additionally injected immediately after axotomy, resulting in a further significant increase in RRR to $22 \%$. This suggests an early activation of proteases during the first $4 \mathrm{~d}$ after $\mathrm{ON}$ transection, which is supported by in vitro data showing an activation of caspases within hours after the apoptotic stimulus (Faleiro et al., 1997; Harvey et al., 1997; Keane et al., 1997).

To characterize the proteases activated after ON transection, we used bio-YVAD-cmk, which preferentially binds subunits of ICE-like proteases in a modified version of the affinity-labeling technique first developed by Thornberry et al. (1994). As has been observed in other models of neuronal apoptosis (Srinivasan et al., 1996; Keane et al., 1997), we detected an active protease with a molecular weight of $\sim 17 \mathrm{kDa}$ that was clearly upregulated after axotomy. ZVAD-fmk treatment could inhibit this upregulation, suggesting a specific mode of action for this protease inhibitor. To date, the only caspase known to be cleaved into 17 and $12 \mathrm{kDa}$ subunits is CPP32 (Enari et al., 1996; Keane et al., 1997). Therefore, we repeated the affinity-labeling experiments using bio-DEVD-CHO, which specifically binds activated CPP32-like proteases (Enari et al., 1996). Under the same experimental conditions, bio-DEVD-CHO also detected the upregulation of a $17 \mathrm{kDa}$ protein after axotomy, as did bio-YVAD-cmk. Moreover, using an antibody against CPP32, we were able to demonstrate activation of CPP32 after lesion. From the data of the affinity labeling and Western blotting, it is not possible to identify the retinal cell type in which CPP32 and/or CPP32-like caspases are activated. Still, the rescue of axotomized RGCs in vivo by caspase inhibition strongly suggests caspase activation in RGCs.

Our findings are in agreement with results derived from ischemic brain lesions in which an important role for CPP32-like proteases has been shown (Asahi et al., 1997; Hara et al., 1997a). The dramatic developmental malformations in the CNS of CPP32 knock-out mice, such as excess cell masses found in several regions of the brain, including the retina, suggest a central role of CPP32 in neuronal apoptosis (Kuida et al., 1996). ICE and ICE-like caspases, however, seem to play only a minor (Asahi et al., 1997) or indirect role (Bhat et al., 1996; Hara et al., 1997b), a view that is supported by the apparently normal phenotype of mice lacking the ICE gene (Kuida et al., 1995; Li et al., 1995). The hypothesis that ICE-like proteases are not essential in neuronal apoptosis would be in agreement with our data, because we failed to detect any known cleavage products of ICE-like proteases in our affinity-labeling experiments. This is all the more surprising, because we first used bio-YVAD-cmk, which has an affinity $>10,000$-fold for ICE-like proteases compared with CPP32-like caspases (Rotonda et al., 1996; see Results). However, we cannot exclude the possibility that our method was not sensitive enough to detect proteases other than those from the CPP32-like family. It is also possible that there are proteases apart from CPP32 that are cleaved to a $17 \mathrm{kDa}$ product, detectable with bio-YVAD-cmk and bio-DEV D-CHO. Using an antibody against CPP32 in Western blot experiments, however, it was possible to identify CPP32 as a regulated caspase. To further clarify the role of CPP32-like proteases in our model, we compared the neuroprotective potential of the wide-range protease inhibitor ZVAD-fmk with the specific CPP32-like caspase inhibitors DEVD-CHO and ZDEVD-cmk in vivo. DEVD-CHO rescued approximately the same number of axotomized RGCs from cell death as ZVADfmk, whereas intraocular injection of the irreversible inhibitor ZDEVD-cmk further enhanced the rescue rate. These results support a central role of CPP32 and CPP32-like proteases in our lesion model.

It is worth noting that we detected a baseline expression of activated caspases in unlesioned control retinae. Because the complete range of substrates processed by caspases is not yet known, we hypothesize that caspases could also be active in cell metabolism under physiological conditions. An alternative explanation would be the immediate activation of caspases during eye 
removal and retina preparation, independent of the respective experimental group.

Overall, complete rescue of axotomized RGCs could not be achieved by either ZVAD-fmk or ZDEVD-cmk treatment. Suboptimal dosage of the protease inhibitors is unlikely, because 400 and $4000 \mathrm{ng}$ injections rescued the same number of RGCs, indicating inhibitor saturation. It is more likely that multiple pathophysiological pathways underlie secondary death of RGCs after axotomy. Of course, caspases are not the only known mediators of neuronal apoptosis. Pathways leading to the activation of protein kinases and transcription factors resulting in subsequent gene induction that can also give rise to apoptosis are reviewed by Lavin et al. (1996). In this context it is worthwhile to note that the apoptosis-related gene bax is upregulated in RGCs after transection of the rat ON within hours (Isenmann et al., 1997). Glutamate-dependent neurotoxicity (excitotoxicity) (Choi, 1988; Lipton and Rosenberg, 1994), which might be at least in part independent of caspase activation, also contributes to delayed death of axotomized neurons as has been shown for cat RGCs (Russelakis-Carneiro et al., 1996). Considering the complex and multiple pathways leading to apoptosis, it is not surprising that factors showing a neuroprotective effect in our model failed to rescue the total RGC population when applied alone. Treatment strategies that combine neuroprotectants antagonizing different presumptive pathways, which result in secondary death, may prove to be much more effective (Klöcker et al., 1998).

One point that remains elusive in this context is whether there is a long-term effect of caspase inhibition on the survival of axotomized RGCs. For BDNF, it has been shown that short-term therapy is not sufficient to guarantee long-lasting RGC survival after ON transection (Mey and Thanos, 1993; Mansour-Robaey et al., 1994). Thus, BDNF might only delay secondary cell death. Whether this holds true for irreversible caspase inhibitors as well or whether they are capable of actually preventing apoptosis and supporting neuronal long-term survival is not yet known.

In summary, we demonstrate here for the first time that CPP32-like caspases are major mediators of apoptosis in RGCs after ON transection and that inhibition of these proteases in our distinct model of neuronal trauma increases the number of surviving neurons after axonal lesion. Together with recent findings in other traumatic CNS injury paradigms (Yakovlev et al., 1997), these results provide evidence for the activation of CPP32-like caspases as a general mechanism of neuronal apoptosis. Consequently, inhibition of CPP32-like caspases might be a very promising strategy in the treatment of various forms of brain injury, including cerebral trauma and neurodegenerative diseases.

\section{REFERENCES}

Alnemri ES, Livingston DJ, Nicholson DW, Salvesen G, Thornberry NA, Wong WW, Yuan JY (1996) Human ICE/CED 3 protease nomenclature. Cell 87:171.

Armstrong RC, Aja T, Xiang J, Gaur S, Krebs JF, Hoang K, Bai X, Korsmeyer SJ, Karanewsky DS, Fritz LC, Tomaselli KJ (1996) Fasinduced activation of the cell death related protease CPP32 is inhibited by $\mathrm{Bcl}-2$ and by ICE family protease inhibitors. J Cell Biol 271:16850-16855.

Armstrong RC, Aja TJ, Hoang KD, Gaur S, Bai X, Alnemri ES, Litwack G, Karanewsky DS, Fritz LC, Tomaselli KJ (1997) Activation of the ced3/ICE-related protease CPP32 in cerebellar granule neurons undergoing apoptosis but not necrosis. J Neurosci 17:553-562.

Asahi M, Hoshimaru M, Uemura Y, Tokime T, Kojima M, Ohtsuka T, Matsuura N, Aoki T, Shibahara K, Kikuchi H (1997) Expression of interleukin- 1 beta converting enzyme gene family and bcl-2 gene family in the rat brain following permanent occlusion of the middle cerebral artery. J Cereb Blood Flow Metab 17:11-18.
Ausubel FM, Brent R, Kingston RE, Moore DD, Seidman JG, Smith JA, Struhl K (1987) Current protocols in molecular biology. New York: Wiley.

Bähr M, Bonhoeffer F (1994) Perspectives on axonal regeneration in the mammalian CNS. Trends Neurosci 17:473-479.

Bähr M, Wizenmann A (1996) Retinal ganglion cell axons recognize specific guidance cues present in the deafferented adult rat superior colliculus. J Neurosci 16:5106-5116.

Bhat RV, DiRocco R, Marcy VR, Flood DG, Zhu Y, Dobrzanski P, Siman R, Scott R, Contreras PC, Miller M (1996) Increased expression of IL-1beta converting enzyme in hippocampus after ischemia: selective localization in microglia. J Neurosci 16:4146-4154.

Cenni, MC, Bonfanti L, Martinou JC, Ratto GM, Strettoi E, Maffei L (1996) Long-term survival of retinal ganglion cells following optic nerve section in adult bcl-2 transgenic mice. Eur $\mathrm{J}$ Neurosci 8:1735-1745.

Chen DF, Schneider GE, Martinou JC, Tonegawa S (1997) Bcl-2 promotes regeneration of severed axons in mammalian CNS. Nature 385:434-439.

Choi DW (1988) Glutamate neurotoxicity and diseases of the nervous system. Neuron 1:623-634.

Cohen GM (1997) Caspases: the executioners of apoptosis. Biochem J 326:1-16.

Cui Q, Harvey AR (1995) At least two mechanisms are involved in the death of retinal ganglion cells following target ablations in neonatal rats. J Neurosci 15:8143-8155.

Enari M, Talanian RV, Wong WW, Nagata S (1996) Sequential activation of ICE-like and CPP32-like proteases during Fas-mediated apoptosis. Nature 380:723-726.

Eschweiler GW, Bähr M (1993) Flunarizine enhances rat retinal ganglion cell survival after axotomy. J Neurol Sci 116:34-40.

Faleiro L, Kobayashi R, Fearnhead H, Lazebnik Y (1997) Multiple species of CPP32 and $\mathrm{MCH} 2$ are the major active caspases present in apoptotic cells. EMBO J 16:2271-2281.

Gagliardini V, Fernandez PA, Lee RK, Drexler HC, Rotello RJ, Fishman MC, Yuan J (1994) Prevention of vertebrate neuronal death by the crmA gene. Science [Erratum (1994) 264:1388] 263:826-828.

Garcia-Valenzuela E, Gorczyca W, Darzynkiewicz Z, Sharma SC (1994) Apoptosis in adult retinal ganglion cells after axotomy. J Neurobiol 25:431-438.

Hara H, Friedlander RM, Gagliardini V, Ayata C, Fink K, Huang Z, Shimizu Sasamata M, Yuan J, Moskowitz MA (1997a) Inhibition of interleukin 1 beta converting enzyme family proteases reduces ischemic and excitotoxic neuronal damage. Proc Natl Acad Sci USA 94:2007-2012.

Hara H, Fink K, Endres M, Friedlander RM, Gagliardini V, Yuan JY, Moskowitz MA (1997b) Attenuation of transient focal cerebral ischemic injury in transgenic mice expressing a mutant ICE inhibitory protein. J Cereb Blood Flow Metab 17:370-375.

Harvey NL, Butt AJ, Kumar S (1997) Functional activation of NEDD2/ ICH 1 (caspase 2) is an early process in apoptosis. J Biol Chem 272:13134-13139.

Isenmann S, Wahl C, Krajewski S, Reed J, Bähr M (1997) Upregulation of bax protein in degenerating retinal ganglion cells precedes apoptotic cell death after optic nerve lesions in the rat. Eur $\mathrm{J}$ Neurosci 9:1763-1772.

Keane RW, Srinivasan A, Foster LM, Testa MP, Ord T, Nonner D, Wang HG, Reed JC, Bredesen DE, Kayalar C (1997) Activation of CPP32 during apoptosis of neurons and astrocytes. J Neurosci Res 48:168-180.

Kinoshita M, Tomimoto H, Kinoshita A, Kumar S, Noda M (1997) Upregulation of the NEDD2 gene encoding an ICE/CED 3-like cysteine protease in the gerbil brain after transient global ischemia. J Cereb Blood Flow Metab 17:507-514.

Klöcker N, Bräunling F, Isenmann S, Bähr M (1997) In vivo neurotrophic effects of GDNF on axotomized retinal ganglion cells. NeuroReport 8:3439-3442.

Klöcker N, Cellerino A, Bähr M (1998) Free radical scavenging and inhibition of nitric oxide synthase potentiates the neurotrophic effects of brain-derived neurotrophic factor on axotomized retinal ganglion cells in vivo. J Neurosci 18:1038-1046.

Kuida K, Lippke JA, Ku G, Harding MW, Livingston DJ, Su MS, Flavell RA (1995) Altered cytokine export and apoptosis in mice deficient in interleukin-1 beta converting enzyme. Science 267:2000-2003. 
Kuida K, Zheng TS, Na S, Kuan C, Yang D, Karasuyama H, Rakic P, Flavell RA (1996) Decreased apoptosis in the brain and premature lethality in CPP32-deficient mice. Nature 384:368-372.

Lavin MF, Watters D, Song Q (1996) Role of protein kinase activity in apoptosis. Experientia (Basel) 52:979-994.

Li P, Allen H, Banerjee S, Franklin S, Herzog L, Johnston C, McDowell J, Paskind M, Rodman L, Salfeld J (1995) Mice deficient in IL-1 beta-converting enzyme are defective in production of mature IL-1 beta and resistant to endotoxic shock. Cell 80:401-411.

Lipton SA, Rosenberg PA (1994) Excitatory amino acids as a final common pathway for neurologic disorders. N Engl J Med 330:613-622.

Mansour-Robaey S, Clarke DB, Wang YC, Bray GM, Aguayo AJ (1994) Effects of ocular injury and administration of brain-derived neurotrophic factor on survival and regrowth of axotomized retinal ganglion cells. Proc Natl Acad Sci USA 91:1632-1636.

Martinou JC, Sadoul R (1996) ICE-like proteases execute the neuronal death program. Curr Opin Neurobiol 6:609-614.

Mey J, Thanos S (1993) Intravitreal injections of neurotrophic factors support the survival of axotomized retinal ganglion cells in adult rats in vivo. Brain Res 602:304-317.

Milligan CE, Prevette D, Yaginuma H, Homma S, Cardwell C, Fritz LC, Tomaselli KJ, Oppenheim RW, Schwartz LM (1995) Peptide inhibitors of the ICE protease family arrest programmed cell death of motoneurons in vivo and in vitro. Neuron 15:385-393.

Nicholson DW, Thornberry NA (1997) Caspases: killer proteases. Trends Biochem Sci 22:299-306.

Rabacchi SA, Bonfanti L, Liu XH, Maffei L (1994) Apoptotic cell death induced by optic nerve lesion in the neonatal rat. $\mathrm{J}$ Neurosci 14:5292-5301.

Roquet N, Pagès JC, Molina T, Briand P, Joulin V (1996) ICE inhibitor YVADcmk is a potent therapeutic agent against in vivo liver apoptosis. Curr Biol 6:1192-1195.

Rotonda J, Nicholson DW, Fazil KM, Gallant M, Gareau Y, Labelle M, Peterson EP, Rasper DM, Ruel R, Vailancourt JP, Thornberry NA, Becker JW (1996) The three dimensional structure of apopain/ CPP32, a key mediator of apoptosis. Nat Struct Biol 3:619-625.

Russelakis-Carneiro M, Silveira LC, Perry VH (1996) Factors affecting the survival of cat retinal ganglion cells after optic nerve injury. J Neurocytol 25:393-402.
Schulz JB, Weller M, Klockgether T (1996) Potassium deprivationinduced apoptosis of cerebellar granule neurons: a sequential requirement for new mRNA and protein synthesis, ICE-like protease activity, and reactive oxygen species. J Neurosci 16:4696-4706.

Slee EA, Zhu H, Chow SC, MacFarlane M, Nicholson DW, Cohen GM (1996) Benzyloxycarbonyl-Val-Ala-Asp (OMe) fluoromethylketone (Z-VAD.FMK) inhibits apoptosis by blocking the processing of CPP32. Biochem J 315:21-24.

Srinivasan A, Foster LM, Testa MP, Ord T, Keane RW, Bredesen DE, Kayalar C (1996) Bcl-2 expression in neural cells blocks activation of ICE/CED-3 family proteases during apoptosis. J Neurosci 16:5654-5660.

Taylor J, Gatchalian CL, Keen G, Rubin LL (1997) Apoptosis in cerebellar granule neurones: involvement of interleukin-1 beta converting enzyme-like proteases. J Neurochem 68:1598-1605.

Thompson CB (1995) Apoptosis in the pathogenesis and treatment of disease. Science 267:1456-1462.

Thornberry NA, Peterson EP, Zhao JJ, Howard AD, Griffin PR, Chapman KT (1994) Inactivation of interleukin-1 beta converting enzyme by peptide (acyloxy)methyl ketones. Biochemistry 33:3934-3940.

Tomita Y, Kawasaki T, Bilim V, Takeda M, Takahashi K (1996) Tetrapeptide DEVD-aldehyde of YVAD-chloromethylketone inhibits Fas/ Apo-1(CD95)-mediated apoptosis in renal-cell-cancer cells. Int J Cancer 68:132-135.

Vasilakos J, Shivers B (1996) Watch for ICE in neurodegeneration. Mol Psychiatry 1:72-76.

Villegas-Perez MP, Vidal-Sanchez M, Bray GM, Aguayo AJ (1988) Influences of peripheral nerve grafts on the survival and regrowth of axotomized retinal ganglion cells in adult rats. J Neurosci 8:265-280.

Yakovlev AG, Knoblach SM, Fan L, Fox GB, Goodnight R, Faden AI (1997) Activation of CPP32-like caspases contributes to neuronal apoptosis and neurological dysfunction after traumatic brain injury. J Neurosci 17:7415-7424.

Yuan J, Shaham S, Ledoux S, Ellis HM, Horvitz HR (1993) The C. elegans cell death gene ced-3 encodes a protein similar to mammalian interleukin-1 beta-converting enzyme. Cell 75:641-652.

Zhu H, Fearnhead HO, Cohen GM (1995) An ICE-like protease is a common mediator of apoptosis induced by diverse stimuli in human monocytic THP.1 cells. FEBS Lett 374:303-308. 